\title{
Molecular evidence for an extinct parent of the tetraploid species Microseris acuminata and M. campestris (Asteraceae, Lactuceae)
}

\author{
D. ROELOFS, * J. VAN VELZEN, † P. KUPERUS and K. BACHMANN‡ \\ Hugo de Vries Laboratory, University of Amsterdam, Kruislaan 318, NL-1098 SM Amsterdam, the Netherlands, Institute for \\ Evolutionary and Ecological Sciences EEW, University of Leiden, Kaiserstraat 63, NL-2311 GP Leiden, the Netherlands, ¥Institute \\ for Plant Genetics and Crop Plant Research IPK, Correnstrasse 3, D-06466 Gatersleben, Germany
}

\begin{abstract}
To determine the origin of the tetraploid annuals Microseris campestris and M. acumina$t a$, chloroplast RFLP, RAPD and ITS sequence variability among nine populations of the two polyploids and 14 populations of the diploid annuals M. elegans and M. douglasii have been surveyed. Previously described variable chloroplast restriction sites infer M. douglasii as the possible maternal parent of both tetraploid species. However, the chloroplast genome typical for $M$. douglasii has now also been found in some plants of M. elegans. RAPD analysis revealed 172 polymorphic DNA markers that defined all four species as genetically distinct groups, but demonstrated closer associations between M. douglasii and M. acuminata, and between M. elegans and M. campestris. Sequencing of the ITS-1 and ITS-2 region yielded 73 phylogenetically informative sites. Thirty basepair mutations separated the annual Microseris species from the outgroup, Uropappus lindleyi. The putative interspecific allotetraploid M. campestris contained only one type ITS sequence that, on the basis of eight synapomorphic substitutions was derived from M. elegans. The single ITS of M. acuminata shares six common sites with M. douglasii. Surprisingly, six sites were synapomorphic for the two tetraploids, M. campestris and M. acuminata, suggesting recombination within the ITS of both species with that of a common, now extinct, parental taxon, possibly the donor of the M. douglasii type chloroplasts found in both tetraploids. These results confirm the interpretation of M. campestris as derived from $M$. douglasii (extinct population) and $M$. elegans, and resolve the unknown origin of $M$. acuminata as an intraspecific hybrid between two very distinct populations of $M$. douglasii, one of them the same extinct $M$. douglasii form that contributes to $M$. campestris.
\end{abstract}

Keywords: chloroplast DNA, concerted evolution, extinct parent, ITS, Microseris, polyploids, RAPD

Received 13 September 1996; revision received 23 January 1997; 4 February 1997

\section{Introduction}

The five tetraploid $(2 \mathrm{n}=36)$ species in the Californian genus Microseris illustrate three very different evolutionary scenarios.

*Present address: Department of Molecular Genetics, Free University, Boelelaan 1087, NL-1081 HV Amsterdam, the Netherlands.

Correspondence: Konrad Bachmann. Fax: + 49-39482-5155, Email: bachmann@mendel.ipk-gatersleben.de
1 The perennial M. scapigera of Australia and New Zealand has arisen from a hybrid between an annual and a perennial species in North America after chromosome duplication and long-distance dispersal (Chambers 1955; Van Houten et al. 1993). Chloroplast DNA analysis (Wallace \& Jansen 1990) suggests that the maternal parent of this hybrid was ancestral to the present-day annuals, and morphological evidence suggests that the paternal parent is related to the present-day M. borealis (Chambers 1955). M. scapigera therefore exemplifies the accidental arrival of a new genetic entity in a geographically isolated 
suitable site from where it has undergone an adaptive radiation into very diverse ecotypes.

2 Two Californian annual tetraploids have to be treated as intergeneric hybrids, after their common paternal parent, Uropappus lindleyi, was removed from Microseris (Jansen et al. 1991). They are Stebbinsoseris heterocarpa (from M. douglasii) and S. decipiens (from M. bigelovii) (Chambers 1955). Both polyploids have arisen repeatedly (Wallace \& Jansen 1995) in areas of sympatry of the respective parental species and have not significantly spread beyond this range.

3 The remaining two tetraploids, M. acuminata and $M$. campestris, together with three diploids, M. douglasii, M. elegans and M. bigelovii form a taxonomically very difficult group of variable forms across California. Chambers (1955) has essentially unravelled the taxonomy of these species and tentatively identified M. douglasii and M. elegans as parents of $M$. campestris. The other tetraploid, M. acuminata, also appears to be an allopolyploid with M. douglasii as one likely parent. Figure 1 , from Chambers (1955), summarizes the possible relationships among the various annuals. Recognition of the two tetraploid entities was a key factor in his analysis. Except for the strictly coastal species, M. bigelovii, the ecological differentiation among the Californian annuals of Microseris is very subtle and they occur frequently in mixed populations. Artificial hybrids among the diploids are at least partially fertile, and the distribution of chloroplast genomes is not congruent with the species borders (Roelofs \& Bachmann 1995, 1997). Still, all of these species appear to retain their identity.
The tetraploids may be as crucial to an understanding of factors involved in the origin and maintenance of the species listed under (3) as they were for the elucidation of their taxonomy. Molecular data provide new sources of evidence for polyploid evolution (Doyle et al. 1990; Soltis \& Soltis 1993; Soltis et al. 1995; Lowe \& Abbott 1996). This investigation was designed to use molecular data to determine the exact parentage of M. acuminat $a$ and M. campestris including evidence for a unique origin or a repeated local origin. This information is essential for a search for factors involved in the apparently stable coexistence of the ecologically similar Californian annuals of Microseris.

\section{Materials and methods}

Four populations of $M$. acuminata, five populations of $M$. campestris, seven populations of $M$. elegans and seven populations of $M$. douglasii have been included in this study (Table 1). These populations have been selected to comprise extremes of variation within each species and to sample sympatric populations of the tetraploids with their putative ancestors. Population E75 of the chosen outgroup species Uropappus lindleyi was sampled in Pima County, Arizona, by Kenton L. Chambers. Offspring of each sample have been raised in the greenhouse for morphological analysis and DNA isolation as previously described (Roelofs \& Bachmann 1995).

Total DNA for chloroplast RFLP analysis was isolated by the maxi preparation method described by Roelofs \& Bachmann (1995). Approximately $2 \mu \mathrm{g}$ DNA was digested with EcoRI or DraI (Eurogentec sa), separated on $0.8 \%$

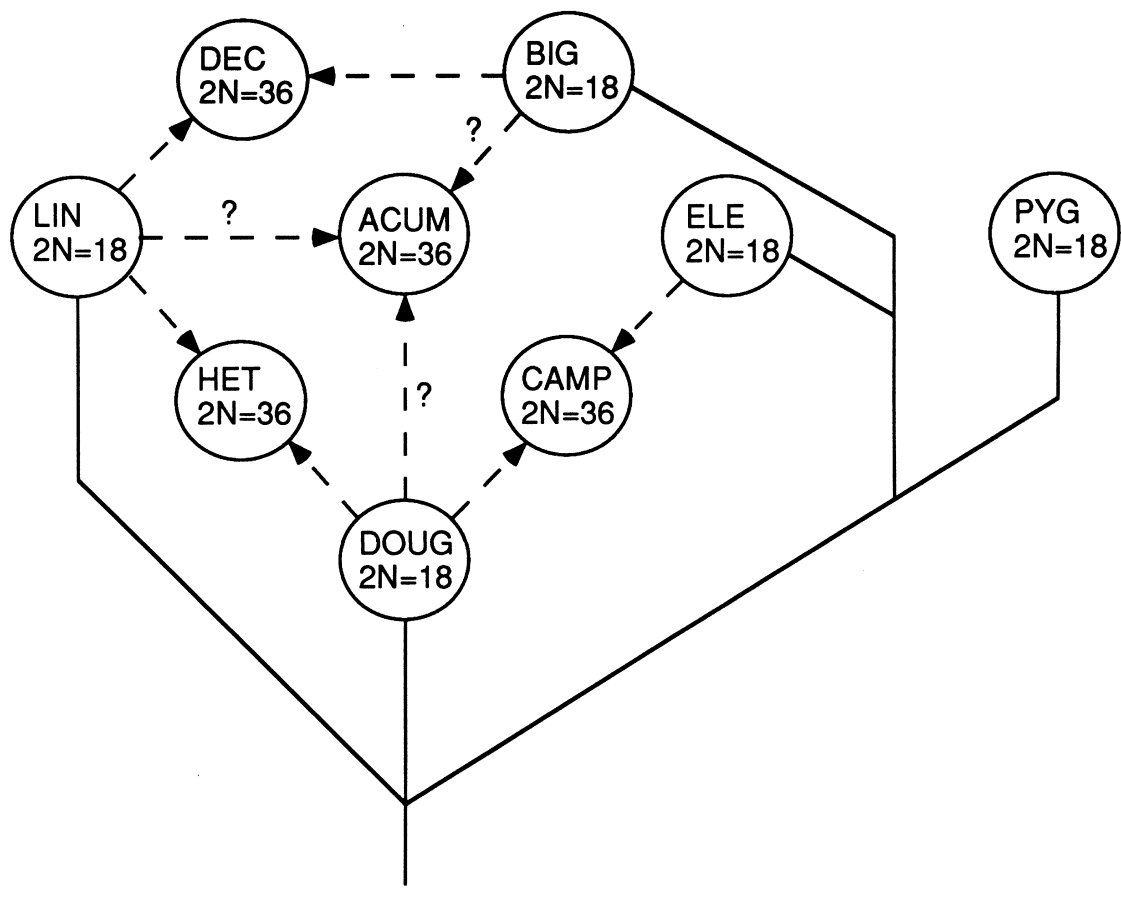

Fig. 1 Phylogenetic relationships of annual Microseris species, outgroup Uropappus lindleyi and the hybrid genus Stebbinsoseris as proposed by Chambers (1955; Jansen $e t$ al. 1991). abbreviations: LIN, U. lindleyi; DEC, S. decipiens; HET, S. heterocarpa; DOUG, M. douglasii; ELE, M. elegans; BIG, M. bigelovii; PYG, M. pygmaea; ACUM, M. acuminata; CAMP, $M$. campestris. Dashed arrows indicate proposed origin of tetraploid annuals. 
Table 1 Collection data and chloroplast genotypes for taxa from annual Microseris species under investigation. All locations are in California. Original accession numbers, county, place of origin and initials of the collectors are listed. Collectors are Kenton L. Chambers ( $\mathrm{CH})$, Johannes Battjes (JB) and James Price (JP). + restriction site present; - restriction site absent.

\begin{tabular}{|c|c|c|c|c|c|}
\hline & \multirow{3}{*}{$\begin{array}{l}\text { Restriction enzyme } \\
\text { Lettuce Sac I probe }(\mathrm{kb})\end{array}$} & \multicolumn{4}{|c|}{ Chloroplast restriction site variants } \\
\hline & & Eco RI & Dra I & $\operatorname{Hinf} \mathrm{I}$ & $\operatorname{Hinf} \mathrm{I}$ \\
\hline & & 7.0 & 12.3 & 7.7 & 14.7 \\
\hline \multicolumn{6}{|c|}{ M. douglasii (diploid $2 \mathrm{n}=18$ ) } \\
\hline E34 & Tehama Co.: Corning Corner, JB and CH & + & - & + & - \\
\hline E52 & San Luis Obispo Co.: Cholame, JB and CH & + & - & + & - \\
\hline E63 & Solano Co.: Cook Lane, JB and CH & + & - & + & - \\
\hline E68 & Colusa Co.: Cortina Ridge, JB and CH & + & - & + & - \\
\hline C57 & San Luis Obispo Co.: Cayucos, JP and CH & - & - & - & - \\
\hline E73 & Riverside Co.: Alberhill mountain, $\mathrm{CH}$ & - & - & - & - \\
\hline F06 & San Diego Co.: San Diego, Santo Road, CH & - & - & - & - \\
\hline \multicolumn{6}{|c|}{ M. elegans (diploid 2n = 18) } \\
\hline E38.1 & Santa Barbara Co.: Dead Man Canyon, JB and CH & - & - & - & + \\
\hline E38.7 & Santa Barbara Co.: Dead Man Canyon, JB and CH & + & - & + & - \\
\hline E40.1 & Santa Barbara Co.: Cottonwood Canyon, JB and $\mathrm{CH}$ & - & - & - & + \\
\hline E40.2 & Santa Barbara Co.: Cottonwood Canyon, JB and $\mathrm{CH}$ & - & - & - & + \\
\hline E40.9 & Santa Barbara Co.: Cottonwood Canyon, JB and $\mathrm{CH}$ & + & - & + & - \\
\hline E48.3 & San Luis Obispo Co.: Cholame I, JB and CH & + & - & + & - \\
\hline E48.5 & San Luis Obispo Co.: Cholame I, JB and CH & + & - & + & - \\
\hline E50.1 & San Luis Obispo Co.: Cholame II, JB and CH & + & - & + & - \\
\hline E50.5 & San Luis Obispo Co.: Cholame II, JB and CH & - & - & - & + \\
\hline E61.1 & Solano Co.: Rio Vista, JB and CH & - & - & - & + \\
\hline E61.5 & Solano Co.: Rio Vista, JB and CH & - & - & - & + \\
\hline E61.18 & Solano Co.: Rio Vista, JB and CH & - & - & - & + \\
\hline E64.6 & Solano Co.: Cook Lane, JB and CH & - & - & - & + \\
\hline E67.1 & Colusa Co.: Cortina Ridge, JB and $\mathrm{CH}$ & - & - & - & + \\
\hline E67.11 & Colusa Co.: Cortina Ridge, JB and CH & - & - & - & + \\
\hline \multicolumn{6}{|c|}{ M. campestris (tetraploid $2 \mathrm{n}=36$ ) } \\
\hline E39.8 & Santa Barbara Co.: Dead Man Canyon, JB and CH & + & - & + & - \\
\hline E41.12 & Santa Barbara Co.: Cottonwood Canyon, JB and $\mathrm{CH}$ & + & - & + & - \\
\hline E49.2 & San Luis Obispo Co.: Cholame I, JB and CH & + & - & + & - \\
\hline E49.3 & San Luis Obispo Co.: Cholame I, JB and CH & + & - & + & - \\
\hline E51.5 & San Luis Obispo Co.: Cholame II, JB and CH & + & - & + & - \\
\hline E51.29 & San Luis Obispo Co.: Cholame II, JB and CH & + & - & + & - \\
\hline E65.1 & Solano Co.: Cook Lane, JB and CH & + & - & + & - \\
\hline E65.16 & Solano Co.: Cook Lane, JB and CH & + & - & + & - \\
\hline \multicolumn{6}{|c|}{ M. acuminata (tetraploid $2 \mathrm{n}=36$ ) } \\
\hline E62.5 & Solano Co.: Rio Vista, JB and CH & + & - & + & - \\
\hline E62.12 & Solano Co.: Rio Vista, JB and CH & + & - & + & - \\
\hline E66.7 & Solano Co.: Cook Lane, JB and CH & + & - & + & - \\
\hline E66.9 & Solano Co.: Cook Lane, JB and CH & + & - & + & - \\
\hline E69.7 & Colusa Co.: Cortina Ridge, JB and CH & + & - & + & - \\
\hline E69.9 & Colusa Co.: Cortina Ridge, JB and CH & + & - & + & - \\
\hline E70.1 & Tehama Co.: Corning Corner, JB and CH & + & - & + & - \\
\hline E70.22 & Tehama Co.: Corning Corner, JB and CH & + & - & + & - \\
\hline
\end{tabular}

agarose gels and blotted on to Qiabrane plus membranes. DNA digested with HinfI (four base-pair recognition site) was separated on $6 \%$ polyacrylamide sequence gels and electroblotted using the methodology described by Van Houten et al. (1993). Hybridization was performed with radioactively labelled Lettuce SacI chloroplast clones described by Jansen \& Palmer (1987).

PCR amplifications for RAPD analysis with DNA mini preparations from one leaf (Hombergen \& Bachmann
1995) were performed with Super Taq polymerase (HT Biotechnologies) in a MJ Research PTC-100/96 thermal cycler as previously described (Roelofs \& Bachmann 1995). Primer kits A, C and H from Operon Technologies (USA) were screened for reliably reproducible polymorphic RAPD markers. The amplification products were separated on $1.5 \%$ agarose gels and visualized by ethidium bromide staining. Gels were scanned with the IS-1000 digital imaging system (Inotech) and evaluated using RFLP $\operatorname{scan}^{\mathrm{TM}}$ 
software (Scanalytics), to produce a binary data set (absence/presence) of RAPD markers.

The internal transcribed spacer region of the ribosomal DNA cistron was sequenced as follows. ITS-1 and ITS-2 regions were amplified separately in a MJ Research PTC$100 / 96$ thermal cycler programmed for $3 \mathrm{~min}$ at $94{ }^{\circ} \mathrm{C}, 35$ cycles of $40 \mathrm{~s}$ at $94{ }^{\circ} \mathrm{C}, 1 \mathrm{~min}$ at $55^{\circ} \mathrm{C}$ and $2 \mathrm{~min}$ at $72{ }^{\circ} \mathrm{C}$, followed by $5 \mathrm{~min}$ at $72{ }^{\circ} \mathrm{C}$. PCR reactions were performed in $25-\mu \mathrm{L}$ reaction mixtures containing $2.7 \mathrm{U}$ of Expand ${ }^{\mathrm{TM}}$ High Fidelity thermostable DNA polymerase (Boehringer Mannheim) together with the supplied buffer, $100 \mu \mathrm{M}$ of each dNTP, $25 \mathrm{ng}$ total DNA and $2 \mu \mathrm{M}$ of each primer. Primers ITS2 and ITS5 were used for amplification of the ITS-1 region and ITS3 and ITS4 were used for amplification of the ITS-2 region (White et al. 1990). Yields of PCR products were checked on low-melting-point agarose gels, cut out and gene cleaned (Bio101 Geneclean ${ }^{\circledR}$ kit II). The fragments were cloned in the pCR-Script ${ }^{\mathrm{TM}} \mathrm{SK}(+)$ vector of the Stratagene cloning kit. Flexiprep mini preparation kit (Pharmacia Biotech) was used to isolate DNA from positive transformed E. coli clones. Sequencing of these clones was performed on an ALF Express ${ }^{\mathrm{TM}}$ automated DNA sequencer using Cy5 labelled Reversed and Universal M13 primers (Pharmacia Biotech).

ITS sequences were aligned with the LASERGENE software package from DNA STAR Inc. PAUP 3.1 (Swofford 1993) was used for phylogenetic analysis. Nucleotide transformations were weighted equally, single base-pair gaps were treated as additional character states; gaps of two or more base pairs were treated as missing data. Split decomposition (Bandelt \& Dress 1992) was performed with SplitsTree 1.0 using a Jukes-Cantor translated distance matrix of all paired ITS sequences as input file.

\section{Results}

All strains were examined for four previously identified cpRFLPs occurring among $M$. douglasii, $M$. elegans and M. bigelovii (Roelofs \& Bachmann 1996). Table 1 shows the chloroplast genotype distribution. Two chloroplast types were present in $M$. douglasii, one type distinguishing 'advanced M. douglasii' (+-+-) from the 'southern' form (-- - ). A third chloroplast type was limited to M. elegans $(---+)$. All M. campestris and all M. acuminata accessions as well as M. elegans accessions E38.7, E40.9, E48.3, E48.5 and E50.1 contain 'advanced M. douglasii' (+- + -) chloroplasts. All other M. elegans accessions contained typical M. elegans chloroplasts.

A total of 60 RAPD primers were tested. Only 11 primers generated 184 clearly reproducible and scorable amplification products, of which 12 were shared among all accessions. The remaining 49 primers were considered not useful for our study, mainly due to problems with reproducibility in the tetraploid samples. Three RAPD markers of the 172 polymorphic bands were shared uniquely among all diploid samples, whereas two were shared uniquely among all tetraploid accessions. Four RAPD bands were shared among all $M$. elegans and $M$. campestris plants and three bands were shared among all $M$. douglasii and M. acuminata plants. One band was shared among all accessions of $M$. douglasii together with all tetraploid plants. Finally, two amplification products were shared among all diploid plants and $M$. campestris. The different ploidy level of the sampled species resulted in incorrect estimates of RAPD variability. Furthermore, the sample size differed among the investigated species (see Table 1). Despite of these problems we analysed the RAPD data set by calculating RAPD band frequency within each species. Individuals within species show enough similarity to cluster as genetically distinct groups. Uncorrected band frequencies (Rfr) within each species were calculated by hand (Rfr, fraction of plants of species j, that contain band i). Assuming that the RAPD bands are independent markers (random mating and random synapsis of homologous chromosomes) we can correct for ploidy level by calculating the band frequency per haploid genome:

tetraploid: $f_{i j}=1-\sqrt[4]{\left(1-R f r_{i j}\right)}$

diploid $f_{i j}=1-\sqrt[2]{\left(1-R f r_{i j}\right)}$

where $f$ is the estimated frequency of RAPD band $i$, in the haploid genome of species $j$ and Rfr is the fraction of the plants of species $j$ that contain the RAPD band $i$.

The pairwise genetic distance was estimated by adding the absolute differences in uncorrected and corrected RAPD band frequency over all bands.

Estimated distance between species $k$ and $l$ :

$D_{k l}=\Sigma\left|f_{i k}-f_{i l}\right|$ (corrected)

$D_{k l}=\Sigma\left|R f r_{i k}-R f r_{i l}\right|$ (uncorrected)

Table 2 lists the absolute pairwise distances between species calculated from RAPD frequency distribution, uncorrected and corrected (bold) for ploidy level. Uncorrected and corrected distances give similar results: $M$. acuminata is more closely related to $M$. douglasii than to M. elegans ( $D$ uncorrected: 40.2, D corrected: 29.9) and $M$. campestris is more closely related to $M$. elegans than to M. douglasii (D uncorrected: $44.7, D$ corrected: 33.3 ).

Five ITS-1 clones and five ITS- 2 clones from each accession (listed in Table 1) were sequenced. From a total of 756 sequenced base pairs 73 were phylogenetically informative. Nucleotide sequences of the total ITS region (ITS-1, 5.8S rDNA, ITS-2) from Microseris species included in this study are registered in the GenBank Nucleotide Sequence Database under accession numbers U69703-U69709. No polymorphisms were found in the coding regions among 
Table 2 Absolute pairwise distances between annual Microseris species based on RAPD frequency distribution Bold numbers show distances corrected for ploidy level. See text for detailed calculations

\begin{tabular}{lcccc}
\hline & douglasii & acuminata & campestris & \multicolumn{1}{c}{ elegans } \\
\hline douglasii & & 40.2 & 51.6 & 59.2 \\
acuminata & & & & 63.9 \\
campestris & $\mathbf{2 9 . 9}$ & 35.6 & & 44.7 \\
elegans & 41.1 & 41.5 & 33.3 & \\
\hline
\end{tabular}

all sampled accessions. ITS-1 clones from $U$. lindleyi, M. pygmaea and M. douglasii E68 and E63 had the same sequences as obtained by Van Houten et al. (1993) for these species. Thirty mutations separated the annual Microseris species from outgroup $U$. lindleyi strain E75. Figure 2 shows the strict consensus of six most parsimonious trees (60 steps long) from a PAUP exhaustive phylogenetic analysis that included the annual diploid Microseris species. Six synapomorphies group M. pygmaea, M. bigelovii, and M. elegans; six base-pair sites unite all $M$. douglasii populations. $M$. douglasii is related to the other three annual diploid species as a monophyletic sister

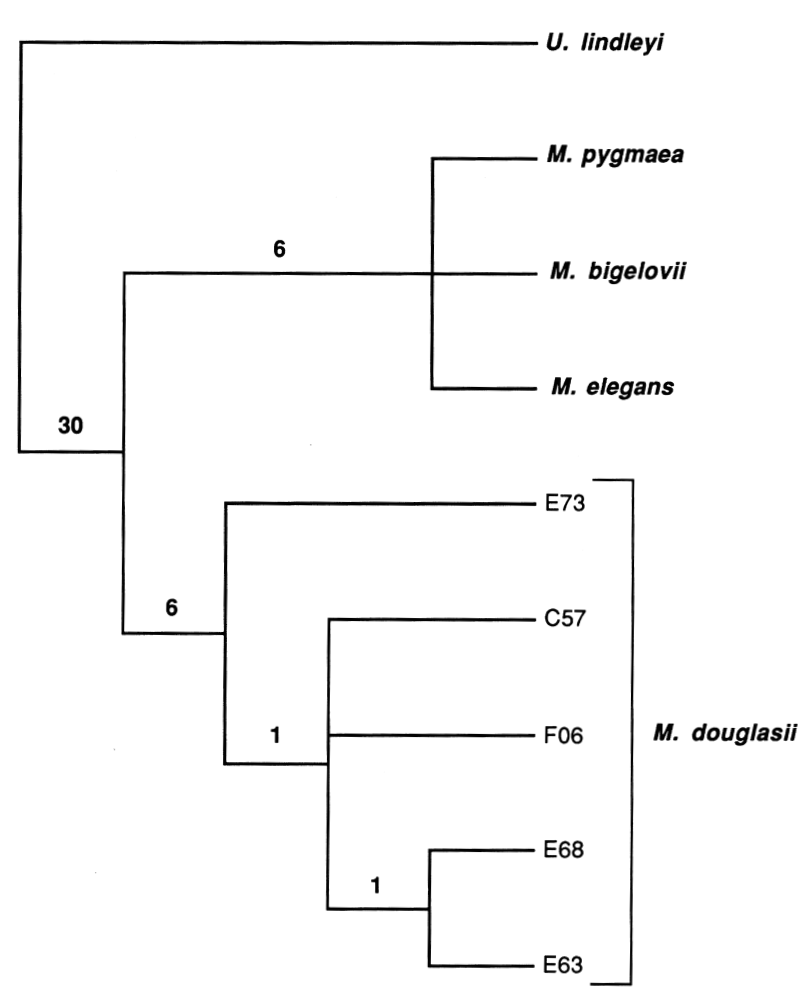

Fig. 2 Strict consensus of six shortest trees (60 steps long, $\mathrm{CI}=0.91$ ) based on 73 phylogenetically informative characters in the $756 \mathrm{bp}$ long total rDNA ITS sequence (ITS-1, 5.8S rDNA and ITS-2) of annual diploid Microseris. Trees were obtained from an exhaustive search using PAUP. Uropappus lindleyi strain E75 was used as outgroup species. Numbers indicate character support for each clade.

(C) 1997 Blackwell Science Ltd, Molecular Ecology, 6, 641-649 group (bootstrap value 94\%). ITS sequences from $M$. douglasii populations E34 and E52 are identical to the core type M. douglasii, in Fig. 2 represented by populations E68 and E63. The southern M. douglasii populations E73, C57 and F06 split off from the core type M. douglasii. After bootstrapping, however, intraspecific sequence variation among strains of $M$. douglasii collapsed into one polytomy.

Analysis of ITS sequences from the two tetraploids demonstrate that both species contain only one ITS sequence each instead of two different ones in the two parental genomes. All six unique $M$. douglasii sites are shared by M. acuminata. All six synapomorphies for the

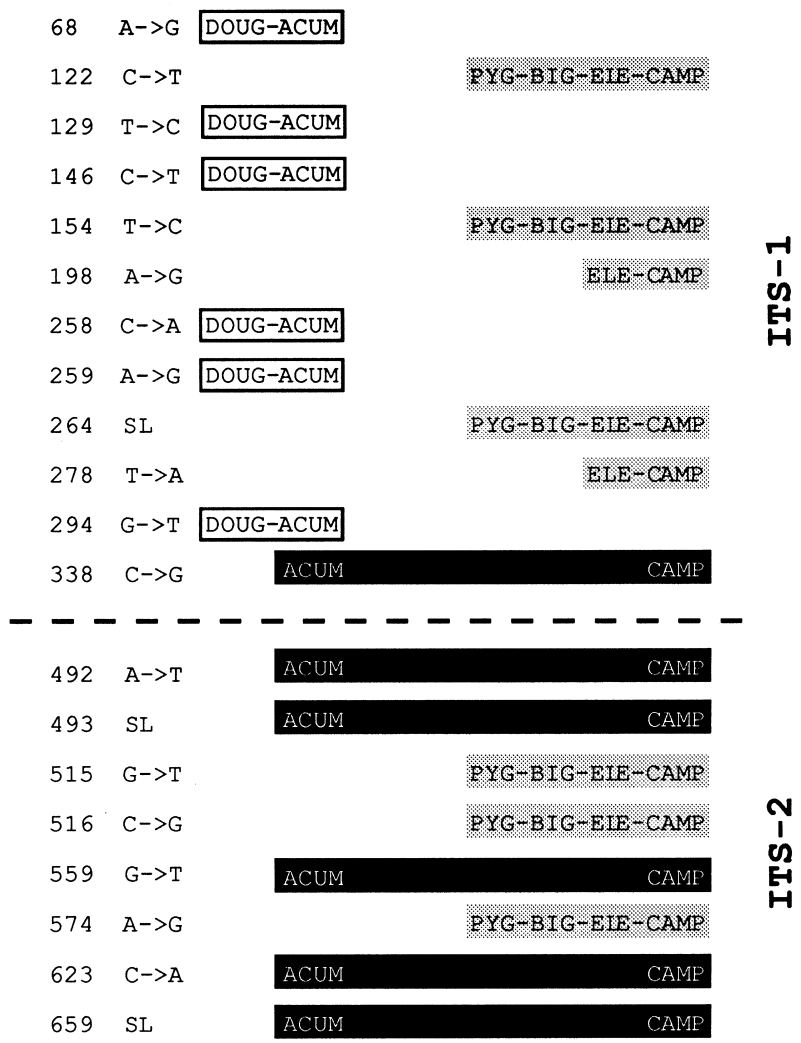

Fig. 3 Distribution of synapomorphic characters in the ITS region. Numbers indicate exact location from the ITS-1 3' origin. Basepair change for each site is indicated; SL, site loss, 1 base pair gap used as phylogenetic character. Abbreviations as in Fig. 1. Synapomorphies comprising typical groupings are illustrated by different boxes. 
three sister species occur in M. campestris, as do two sites autapomorphic in M. elegans. M. acuminata contains six intraspecific mutations, of which three were found in the highly variable population E62. Unexpectedly, $M$. campestris and $M$. acuminata share six unique mutations, of which one is located at the end of ITS-1 (position 338 in Fig. 3) and the remaining five are present throughout ITS-2. All mutations that unite M. douglasii with $M$. acuminata (doug-acum) occur in the ITS-1 region. Synapomorphies grouping $M$. campestris with the three diploids (pyg-big-ele-camp) occur throughout the complete ITS region. Synapomorphies that unite $M$. douglasii with $M$. campestris and M. acuminata were not found.

Split decomposition (Fig. 4a) analysis and parsimony analysis (Fig. 2) of diploid ITS sequences yielded a similar tree structure. Figure 4(b) shows the result of SplitsTree analysis including the tetraploids. M. campestris groups with $M$. elegans based on eight synapomorphies and M. acuminata shares six synapomorphies with M. douglasii. The six sites shared by all tetraploids sampled in this study force the graph from a tree structure into a box-like representation.

\section{Discussion}

Both tetraploid species show an identical chloroplast RFLP pattern $(+-+-)$ that is concordant with a chloroplast type present in 'advanced' M. douglasii (Roelofs \& Bachmann 1996). Except for one reported case in Coreopsis (Mason et al. 1994) the chloroplast genome is maternally inherited in Asteraceae (Corriveau \& Coleman 1988), and therefore provides a suitable maternal marker in species with a reticulate phylogeny. In our case, the conclusion that $M$. douglasii is the maternal ancestor of both tetraploids is hampered by the fact that four of the seven sampled $M$. elegans populations contain 'advanced' $M$. douglasii $(+-+-)$ chloroplasts as well. At least three of these populations are polymorphic together with the 'normal' M. elegans $(---+)$ chloroplast type. This is a new observation for $M$. elegans and suggests cytoplasmic introgression at the diploid level. Recently Roelofs \& Bachmann (1995, 1996, in press) investigated cytoplasmic introgression from M. bigelovii into M. douglasii and concluded that natural hybridization between $M$. bigelovii and M. douglasii followed by selective elimination of the $M$. bigelovii nuclear genome accounts for $M$. bigelovii chloroplast capture in M. douglasii. Chambers (1955) inferred the origin of tetraploid M. campestris as the result of natural hybridization between $M$. douglasii and M. elegans. It seems likely that similar processes account for $M$. douglasii cytoplasm capture in diploid M. elegans.

RAPDs represent a more or less random set of dominant markers throughout the genome. Besides problems of reproducibility and allelism (Bachmann 1994; Whitkus et
A

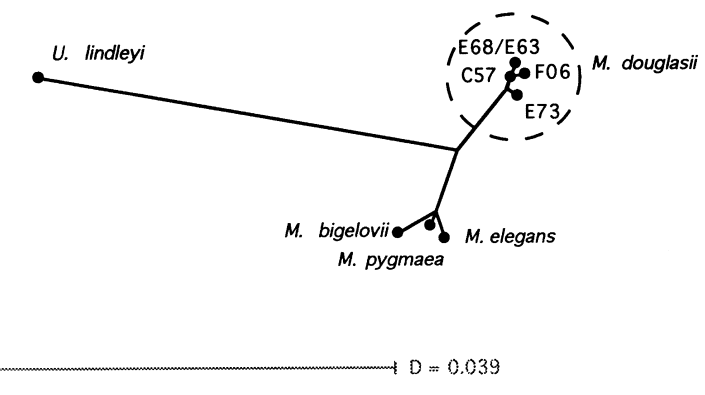

B

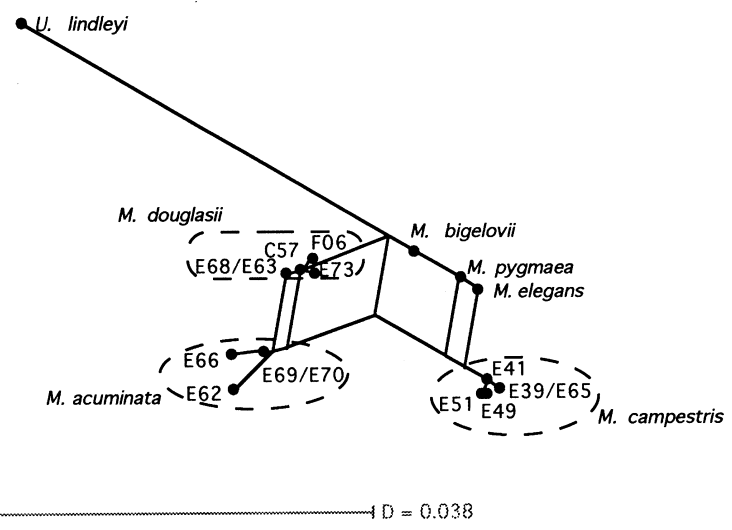

Fig. 4 Split decomposition with SplitsTree 1.0 using a Jukes-Cantor translated distance matrix of all paired ITS sequences as input file. (A) analysis of diploid annual Microseris together with outgroup Uropappus lindleyi. (B) tetraploid species $M$. acuminata and $M$. campestris included in the analysis. D, Jukes-Cantor genetic distance of longest branch (dashed line)

al. 1994; Clark \& Lanigan 1993) it is difficult to compare individuals with different ploidy levels due to quantitative polymorphisms (Williams et al. 1993). In an attempt to account for ploidy level in our comparison of di- and tetraploids, RAPD band frequencies for the haploid genome of each species were estimated. However, in these corrected calculations we assumed that random mating and random synapsis of homologous chromosomes occurs, which may not be the case in the allotetraploids surveyed in this study. M. acuminata and M. campestris will still show a higher RAPD band frequency due to their higher ploidy level and this causes a bias in the uncorrected distances. The real genetic distance values will probably be inbetween uncorrected and corrected calculations. However, corrected and uncorrected distance measures both indicate that $M$. campestris is more closely related to $M$. elegans than to $M$. douglasii, and M. acuminata is more closely related to M. douglasii than to M. elegans (Table 2).

(C) 1997 Blackwell Science Ltd, Molecular Ecology, 6, 641-649 
Apparently, most of the variability in the RAPD patterns must have arisen after tetraploid speciation, so that only few markers of putative parental species are found in present tetraploid genomes.

ITS sequences gave more insight into the composition of the nuclear genomes of the two tetraploids. Individuals of both tetraploids contained only a single ITS sequence each instead of two different ones in the two parental genomes. This must be the result of sequence homogenization including recombination between the two parental ITS sequences combined in the original hybrid. The putative diploid parents, M. douglasii and M. elegans, are easily distinguishable (Fig. 2). M. acuminata contains an M. douglasii derived ITS- 1 and M. campestris contains an M. elegans derived ITS-1. From the end of ITS-1 (basepair 338, Fig. 3) and into the ITS-2, M. acuminata and $M$. campestris share six mutations that are absent in the remaining annual Microseris species. Because a common tetraploid ancestry of the two species is excluded, these 'synapomorphies' may be derived from a common diploid parent for both tetraploids that has contributed part of its ITS sequence through recombination with that of the respective other parent. One single recombination event somewhere between basepairs 294 and 338 of ITS-1 can explain the pattern observed in M. acuminata, while several recombination events throughout ITS-2 may have occurred in M. campestris. It is tempting to postulate that this hypothetical common parent introduced the M. douglasii type chloroplasts into both species, except for our new observation that $M$. douglasii type chloroplasts occur in some diploid M. elegans. The exact nature of this hypothetical taxon remains uncertain. Based on similarities in morphology between $M$. campestris and $M$. douglasii we can tentatively assign the unknown ancestor to $M$. douglasii. The fact that about half of the genomes of all M. acuminata and M. campestris should be derived from this hypothetical ancestor suggests that it will be possible to reconstruct much of its diploid genome from shared polymorphisms and to thus check its phylogenetic position.

Recombination among the two ITS regions combined in an allotetraploid was first demonstrated in the Australian allotetraploid M. scapigera (Van Houten et al. 1993). In general an allotetraploid behaves as a diploid by forming only bivalents during meiosis I (amphidiploid); the rDNA regions of the different parental species do not synapse in an alloploid during meiotic prophase. In his cytogenetic study Chambers (1955) observed only bivalents in the meiosis I of $M$. campestris. Thus two parental ITS sequences are expected to be present in an allotetraploid. Wendel et al. (1995) observed interlocus homogenization of ITS sequences in Gossypium alloploids and suggested mitotic and meiotic unequal crossing over between repeats from different chromosomes. Gossypium rDNA arrays are located on telomeric and subtelomeric chromosomal loci, which may allow sporadic pairing and exchange between homologous rDNA loci without deleterious cytogenetic effects.

On the basis of this study and previous studies (Chambers 1955; Wallace \& Jansen 1990; Jansen et al. 1991; Van Houten et al. 1993; Wallace \& Jansen 1995; Roelofs \& Bachmann 1997) we now propose a nearly completely resolved phylogenetic relationship among all annual Microseris species, including tetraploids derived through reticulation (Fig. 5). The hypothetical extinct parent of M. acuminata and M. campestris is the second extinct

Fig. 5 Proposed phylogeny of all annual Microseris species together with tetraploids involved in reticulate evolution. Dashed lines indicate origin of each tetraploid species.

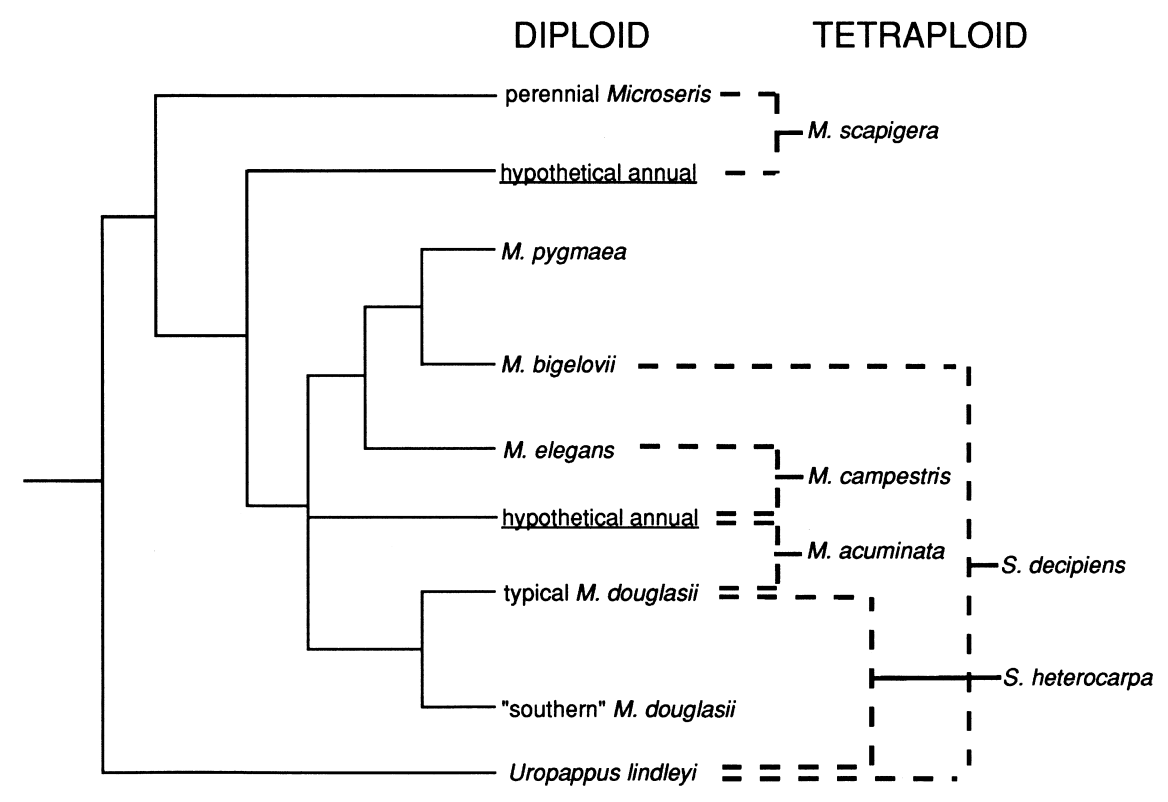

(C) 1997 Blackwell Science Ltd, Molecular Ecology, 6, 641-649 
annual inferred from molecular data. Previously, the annual parent of the Australian M. scapigera was inferred from the chloroplast genome of the species (Wallace \& Jansen 1990). The possibility to reconstruct extinct parents from traces of their sequences in allotetraploid derivatives illustrates the power of molecular evidence. At the same time, it points to potential difficulties in the reconstruction of reticulate evolution at the diploid level where the inference of extinct taxa is much more difficult.

Our inference of an extinct parent presents a simple solution to the uncertainties surrounding the origin of M. acuminata (Chambers 1955). M. acuminata is a well-circumscribed taxon with very little intraspecific variation as compared to the diploid annuals. The extinction of one of the ancestral taxa precludes a recurrent origin of M. acuminata. Considering the difficulty of demonstrating factors limiting the geographical distribution and free association of alleles in the diploid taxa (Roelofs \& Bachmann 1995, 1996; in press), the lack of variation in M. acuminata is more likely to reflect an origin of this taxon from a single hybridization event than specific adaptation.

Detecting the same extinct parent in $M$. campestris in place of a recent $M$. douglasii is more of a surprise. M. campestris is more variable than M. acuminata, and its morphological polymorphisms parallel similar variable characters of achenes and pappus in $M$. douglasii and M. elegans (Chambers 1955), even though no covariation in mixed populations could be demonstrated. The present study was designed to reveal such common polymorphisms and reveal possible independent local origins of M. campestris. The contribution of the extinct parent precludes such a simple explanation for the variability in M. campestris. The greater genetic variation in $M$. campestris as compared to M. acuminata could reflect remnants of multiple origins. Because we are aware of the extinct parental taxon we can now search for traces of its genome by looking for shared characters among M. acuminata and M. campestris and try to place these in the phylogeny of the diploids.

\section{Acknowledgements}

We thank Kitty Vijverberg and Inge Tas for comments on the manuscript and Louis Lie for assistance in the greenhouse and analysis of capitulum characters.

These investigations were supported by the Life Science Foundation (SLW, grant 805-38162) which is subsidized by the Netherlands Organization for Scientific Research (NWO).

\section{References}

Bachmann K (1994) Molecular markers in plant ecology. New Phytologist, 126, 403-418.

Bandelt HJ, Dress AWD (1992) Split decomposition: a new and useful approach to phylogenetic analysis of distance data. Molecular Phylogenetics and Evolution, 1, 242-252.
Chambers KL (1955) A biosystematic study of the annual species of Microseris. Contributions to the Dudley Herbarium, 4, 207-312.

Clark AG, Lanigan CMS (1993) Prospects for estimating nucleotide divergence with RAPDs. Molecular Biology and Evolution, 10, 1096-1111.

Corriveau JL, Coleman AW (1988) Rapid screening method to detect potential biparental inheritance of plastid DNA and results over 200 angiosperm families. American Journal of Botany, 75, 1443-1458.

Doyle JJ, Doyle JL, Brown AHD, Grace JP (1990) Multiple origins of polyploids in Glycine tabacina complex inferred from chloroplast DNA polymorphism. Proceedings of the National Academy of Sciences of the United States of America, 87, 714-717.

Hombergen EJ, Bachmann K (1995) RAPD mapping of 3 QTLs determining trichome formation in Microseris Hybrid H27 (Asteraceae, Lactuceae). Theoretical and Applied Genetics, 90, 853-858.

Jansen RK, Palmer JD (1987) Chloroplast DNA from Lettuce and Barnadesia (Asteraceae): structure, gene localization, and characterization of a large inversion. Current Genetics, 11, 553-564.

Jansen RK, Wallace RS, Kim KJ, Chambers KL (1991) Systematic implications of chloroplast DNA variation in the subtribe Microseridinae (Asteraceae: Lactuceae). American Journal of Botany, 78, 1015-1027.

Lowe AJ, Abbott RJ (1996) Origins of the new allopolyploid species Senecio cambrensis (Asteraceae) and its relationship to the Canary Island endemic Senecio teneriffae. American Journal of Botany, 83, 1365-1372.

Mason RJ, Holsinger KE, Jansen RK (1994) Biparental inheritance of the chloroplast genome in Coreopsis (Asteraceae). Journal of Heredity, 85, 171-173.

Roelofs D, Bachmann K (1995) Chloroplast and nuclear DNA variation among homozygous plants in a population of the autogamous annual Microseris douglasii (Asteraceae, Lactuceae). Plant Systematics and Evolution, 196, 185-194.

Roelofs D, Bachmann K (1997) Comparison of chloroplast and nuclear phylogeny in the autogamous annual Microseris douglasii (Asteraceae, Lactuceae). Plant Systematics and Evolution, 204, 49-63.

Roelofs D, Bachmann K (in press) Genetic analysis of a Microseris douglasii population polymorphic for an alien chloroplast type. Plant Systematics and Evolution.

Soltis PS, Plunkett GM, Novak SJ, Soltis DE (1995) Genetic variation in Tragopogon species: additional origins of the allotetraploids T. mirus and T. miscellus (Compositae). American Journal of Botany, 82, 1329-1341.

Soltis PS, Soltis DE (1993) Molecular data and the dynamic nature of polyploidy. Critical Reviews in Plant Sciences, 12, 243-273.

Swofford DL (1993) PAUP: Phylogenetic Analysis Using Parsimony, version 3.1 . Formerly distributed by Illinois Natural History Survey, Champaign, Illinois.

Van Houten WJH, Scarlett N, Bachmann K (1993) Nuclear DNA markers of the Australian tetraploid Microseris scapigera and its North American diploid relatives. Theoretical and Applied Genetics, 87, 498-505.

Wallace RS, Jansen RK (1990) Systematic implications of chloroplast DNA variation in the genus Microseris (Asteraceae: Lactuceae). Systematic Botany, 15, 606-616.

Wallace RS, Jansen RK (1995) DNA evidence for multiple origins of intergeneric alloploids in annual Microseris (Asteraceae). Plant Systematics and Evolution, 198, 253-265.

(C) 1997 Blackwell Science Ltd, Molecular Ecology, 6, 641-649 
Wendel JF, Schnabel A, Seelanan T (1995) Bidirectional interlocus concerted evolution following allopolyploid speciation in cotton (Gossipium). Proceedings of the National Academy of Sciences of the United States of America, 92, 280-284.

White TJ, Bruns T, Lee S, Taylor J (1990) Amplification and direct sequencing of fungal ribosomal RNA genes for phylogenetics. In: PCR protocols: a guide to methods and applications (eds Innes MA, Gelfand DH, Sninsky JJ, White TJ), pp. 315-322. Academic Press, San Diego.

Whitkus R, Doebley J, Wendel JF (1994) Nuclear DNA markers in systematics and evolution. In: DNA-Based Markers in Plants (eds Phillips RL, Vasil IK), pp. 116-141. Kluwer Academic Publishers, Dordrecht.

Williams JG, Hanafey MK, Rafalski JA, Tingey SV (1993) Genetic analysis using random amplified polymorphic DNA markers. Methods in Enzymology, 218, 704-740.

The authors are interested in reticulate evolution and its consequences in angiosperm plants. Molecular methods are being used to study processes like cytoplasmic introgression and hybrid speciation at the DNA level. 